\title{
Urdimento
}

Revista de Estudos em Artes Cênicas

E-ISSN: 2358.6958

\section{Memórias ao sol: em busca de uma dramaturgia da escuta com mulheres em privação de liberdade}

Caroline Vetori de Souza

\section{Para citar este artigo:}

SOUZA, Caroline Vetori de. Memórias ao sol: em busca de uma dramaturgia da escuta com mulheres em privação de liberdade. Urdimento, Florianópolis, v. 3, n. 39, nov./dez. 2020.

DOI: http:/dx.doi.org/10.5965/14145731033920200114 
Memórias ao sol: em busca de uma dramaturgia da escuta com mulheres em privação de liberdade

Caroline Vetori de Souza ${ }^{1}$

\begin{abstract}
Resumo
No presente artigo analisa-se um processo artístico-pedagógico com mulheres em situação de cárcere em 2019 no Presídio Feminino de Florianópolis, em Santa Catarina. Compreende-se que uma das estratégias da prisão é a invisibilização das pessoas a ela submetidas, sendo que suas histórias são construídas por outros e, mesmo alicerçadas em estigmas, procurou-se ir na contramão desses processos. Assim, as proposições da oficina tiveram como foco o desenvolvimento de práticas que convocassem uma reapropriação e ressignificação das histórias de vida, a partir do terreno do teatro. Buscou-se, a partir da escuta dos materiais gerados e do próprio processo, a construção de uma escrita que não omitisse as vozes das mulheres que fizeram a oficina, mas que, pelo contrário, colocasse-as em foco.
\end{abstract}

Palavras-chave: Pedagogia do Teatro. Presídio Feminino. Dramaturgia da escuta. Memórias ao sol.

\title{
Memories in the sun: in search of a dramaturgy of listening with women in deprivation of freedom
}

\begin{abstract}
This article analyzes an artistic-pedagogical workshop with incarcerated women. The workshop took place in 2019, at the Women's Prison of Florianópolis, in the State of Santa Catarina, Brazil. Prisons strategically makes its subjects invisible, as their stories are constructed by other people and based on stigmas. The author and her collaborators tried to go against these strategies. Thus, the workshop focused on the development of practices intended to enable the reappropriation and re-signification of the participants' life stories, using theater. Drawing on the theatrical devising process used with the women, this article attempts not to omit the voices of the women who participated in the workshop but to bring them into focus.
\end{abstract}

Keywords: Theater Pedagogy. Female prison. Dramaturgy of listening. Memories in the sun.

1 Doutoranda em Teatro pela UDESC. Mestra em Teatro pela UDESC. Licenciada em Teatro pela UFRGS. vetoricaroline@gmail.com 


\section{Recuerdos al sol: en busca de una dramaturgia de escucha con mujeres em privación de libertad}

\section{Resumen}

Este artículo analiza un proceso artístico-pedagógico con mujeres em prisión, que tuvo lugar em 2019, en el Penal de Mujeres de Florianópolis, em Santa Catarina. Al comprender que una de las estrategias de la prisión es la invisibilidad de las personas sometidas a ella, ya que sus historias son construidas por otros e incluso a partir de estigmas, intentamos ir en contra de estos procesos. Así, las propuestas del taller se centraron em el desarrollo de prácticas que exigían una reapropiación y re significación de las historias de vida, a partir del terreno del teatro. A partir de escuchar los materiales generados y el proceso em sí, buscamos construir una escritura que no omitiera las voces de las mujeres que hicieron el taller, pero que estuvieran enfocadas.

Palabras clave: Pedagogía Teatral. Prisión Femenina. Dramaturgia de escucha. Recuerdos al sol. 
O presente artigo analisa uma prática artístico-pedagógica que aconteceu de fevereiro a novembro de 2019 dentro do Presídio Feminino de Florianópolis. A prática se insere dentro das ações do projeto de extensão Pedagogia do teatro e processos de criação e do projeto de pesquisa Teatro e prisão: práticas de infiltração das artes cênicas em espaços de vigilância, ambos sob coordenação do prof. Dr. Vicente Concilio². A prática estava atrelada a minha pesquisa de mestrado, que tinha como ponto de partida as histórias de vida das participantes.

Questiono como eu, enquanto propositora e parceira de um trabalho envolvendo vozes oprimidas, desenvolvi procedimentos para que emergisse uma escritura que não omitisse as vozes das mulheres com as quais trabalhei, mas que estas estivessem no foco, conclamando a minha escuta nesse processo e, após, a escuta das pessoas que dialogaram com a peça fruto desse percurso. Em decorrência, tendo como esteio a escuta, lidando com o que tenho chamado de dramaturgia da escuta.

É a partir das reflexões de John Holloway ${ }^{3}$ (2013), em específico em Fissurar o capitalismo, que ancorei minhas proposições. Para Holloway, a revolução acontecerá através de nossa recusa em seguir alimentando o sistema capitalista, visto que somos perpetuadoras desse sistema. Então, a inconformidade com o sistema deve se reverter na busca de abrir fissuras neste, através de outras práticas.

As fissuras como possibilidade de

[...] abertura de um mundo que se apresenta como fechado. É a abertura de categorias que em sua superfície negam o poder do fazer humano, para descobrir em seu núcleo o fazer negado e encarcerado. (Holloway, 2013, p. 12).

O método da fissura possui como base o duplo "recusa-e-criação" (Holloway 2013). Sendo assim, antes de analisar as criações, faz-se necessário dar alguns passos atrás, para discutir algumas das características da instituição prisão e

${ }^{2}$ Doutor em teatro, pesquisador e professor na Universidade do Estado de Santa Catarina (UDESC).

${ }^{3}$ Filósofo irlandês, economista e professor na Universidade Autônoma de Puebla, no México. 
marcas por ela imputadas às pessoas que são encarceradas, visto que a prática se insere nesse complexo contexto e a partir do qual nasceram outras propostas.

\section{Ruína em evidência: e se as vozes fossem escutadas?}

Todas as pessoas que já buscaram, por alguma motivação social, entrar em uma prisão, como para propor um projeto, sabem da dificuldade que se insurge. Aquelas $^{4}$ que não têm em suas trajetórias algum atravessamento do cárcere, apesar de não conhecerem a realidade de uma prisão, possuem uma ideia acerca de sua função e mesmo um imaginário bem constituído, vendo-a como natural ${ }^{5}$ no enquadramento da sociedade contemporânea ocidental.

Angela Davis ${ }^{6}\left(2018^{7}\right)$ atenta para a ideologia que delineia nossa relação enquanto indivíduos com a instituição prisão, a qual figura no imaginário numa relação entre ausência e presença, apontando para o modo como agimos em relação a ela: naturaliza-se sua existência, mas não enfrenta-se sua realidade, visto que, ao ter como característica o muramento e fechamento, opera como espaço fora do âmbito social. Ainda, a estudiosa estadunidense revela que há uma história da visualidade articulada à prisão, havendo um grande número de produções audiovisuais que corroboram para a naturalização da existência dessa instituição.

Como produto da passagem pela prisão, há, ainda, o delineamento de um perfil específico a quem foi submetida a ela. Segundo Michel Foucault ${ }^{8}$ (2008), em

\footnotetext{
${ }^{4}$ Lançarei mão neste artigo de pronomes femininos. Não me alinho à compreensão da utilização do artigo masculino como universal.

${ }^{5}$ Naturalização que incide diretamente nas pessoas que são submetidas à instituição. Conforme expõe Ana Luiza Flauzina (2006), "a partir do discurso racista da inferioridade negra, o manejo do sistema penal, principalmente pela difusão do medo e seu poder desarticulador, cumpriu um papel fundamental nos processos de naturalização da subalternidade." (2006, p.50).

${ }^{6}$ Filósofa, ativista, docente e pesquisadora de profícua contribuição sobre discussões de gênero, raça e classe. Possui intensa militância quanto aos movimentos de mulheres e de negros e com forte discurso contra o aprisionamento em massa da população negra. Atuando nos Estados Unidos, que é sua origem, mas se estendendo a diversos outros país com suas reflexões.

${ }^{7}$ Estarão as prisões obsoletas?, de 2003, mas publicado tardiamente no Brasil em 2018.

8 Filósofo, psicólogo, pesquisador. Em vida, foi professor da cátedra História dos Sistemas do Pensamento, no Collège de France, na França.
} 
Vigiar e punir: nascimento da prisão, encoberta sobre o discurso da reabilitação, uma das funções da prisão é a construção da delinquência, que dá-se através da estigmatização ${ }^{9}$ das pessoas que passaram pela instituição, corroborando para a manutenção do próprio sistema. As grandes mídias auxiliam na criação dessas imagens estigmatizantes, corroborando para a ideia de necessidade da instituição prisão, além de sua naturalização, colocando, por exemplo, as pessoas encarceradas em situações degradantes ou mesmo, como protagonistas de insurgências contra o sistema, colando a suas imagens a ideia de perigo social e decorrente medo.

Sabemos que uma das formas de manutenção do status quo é a conformação. Assim, a leitura crítica da instituição punitiva não deve cair numa narrativa fatalista, mas, através de ações, buscar brechas para que possamos esboçar outras formas de responsabilização e organização social. Em decorrência, olhando para o campo no qual atuo, indago quais são as possibilidades que podemos entrever, visto que o teatro é campo frutífero para a proposição de outros imaginários. É a partir dessa questão que compartilho uma ação poética que buscou contrapor-se à lógica da instituição prisão, abrindo algumas fissuras.

Em específico quanto às pessoas encarceradas, um dos procedimentos inerentes à prisão é a invisibilização dessas pessoas. Invisibilização que dá-se através da compreensão do outro como objeto, ação própria da colonialidade. Grada Kilomba10, em Memórias da plantação (2019), discute um dos pressupostos do projeto colonial, que ainda reverbera, que é o delineamento de sujeitos e objetos. A partir de bell hooks"11, a autora compartilha a definição de objetos, que são criações de outros, nos quais a "história designada somente de maneiras que definem (nossa) relação com aqueles que são sujeitos." (hooks apud Kilomba, 2019,

${ }^{9}$ Erving Goffman, em Estigma: notas sobre a manipulação da identidade deteriorada, de 1975, se debruça sobre temática do estigma. Segundo o autor, "a sociedade estabelece os meios de categorizar as pessoas e o total de atributos considerados como comuns e naturais para os membros de cada uma dessas categorias" (Goffman, 1975, p. 12). Assim, percebe-se a construção do estigma sob um viés normativo, apontando que tudo que foge a tal norma é desviante.

${ }^{10}$ Artista interdisciplinar, psicóloga, pesquisadora e professora na Universidade de Humboldt, em Berlim, na área de Estudos de Gênero e Estudos Pós-Coloniais.

${ }^{11}$ Teórica feminista, ativista social e professora no City College, em Nova York, nos Estados Unidos. 
p. 28).

Kilomba (2019) aponta que escrever pode ser um ato de descolonização,

[...] no qual quem escreve se opõe a posições coloniais tornando-se a/o escritora/escritor 'validada/o' e 'legitimada/o' e, ao reinventar a si mesma/o, nomeia uma realidade que fora nomeada erroneamente ou sequer fora nomeada. (Kilomba, 2019, p. 28).

Assim, um primeiro passo contra-hegemônico, é lançar o olhar para as produções narrativas das pessoas dentro do contexto do cárcere, encontrando modos de auxiliar na produção e na visibilização destas pelas próprias pessoas que estão nessa situação.

Na produção discursiva dentro do contexto de privação de liberdade, as pessoas encarceradas são destituídas de seu lugar de enunciação, visto que suas histórias são contadas (e construídas) por outrem, como dá-se no processo judicial. Como construir processos para a reapropriação e ressignificação das próprias histórias de vida? Esta era uma das questões geradoras da oficina de teatro proposta.

\section{Presídio Feminino de Florianópolis: condições ou condicionantes?}

Os encontros da oficina de teatro no Presídio Feminino de Florianópolis se deram semanalmente, aos sábados, com três horas de duração cada - a proposta fora aceita pela direção da instituição, através da submissão de um projeto, e as participantes tiveram direito à remição ${ }^{12}$ de suas penas pela atividade. Ao final do processo, totalizaram-se 38 encontros, 114 horas, além de duas apresentações teatrais.

A condução do trabalho foi compartilhada, visto que tratava-se da única unidade em Florianópolis que possuía uma oficina de teatro de caráter

${ }^{12} \mathrm{O}$ direito à possibilidade de remição consta na Lei de Execução Penal, no qual a pessoa que "cumpre a pena em regime fechado ou semiaberto poderá remir, por trabalho ou por estudo, parte do tempo de execução da pena". 
permanente, operando como uma incubadora para futuras práticas ${ }^{13}$. Compuseram, então, a equipe de trabalho, além de mim, Alexandra de Melo ${ }^{14}$, Naguissa Takemoto ${ }^{15}$, Thuanny Paes $^{16}$, contando com a orientação do prof. Dr. Vicente Concilio.

Buscamos, a partir de nossas vivências na oficina, encontrar modos de condução das aulas, como a divisão das proposições, para não nos interferirmos e, ainda, para que cada uma tivesse seu momento de condução, materializando o exercício docente (compreendendo a oficina também como um espaço formativo singular para as próprias mediadoras).

Ao longo do processo chegamos a contar com 15 estudantes, número que variou no decorrer de nosso percurso, visto o contexto do trabalho, no qual as estudantes são transferidas ou soltas e, até mesmo, houve aquelas que não se identificaram com a prática proposta.

Nossas aulas aconteceram em dois espaços; no começo em uma sala que possuía três paredes de concreto e uma grade de fora a fora. Nessa sala podia-se ver o portão de entrada, assim, em muitos momentos as estudantes distraiam-se com a movimentação da unidade, e nós erámos interrompidas. Após, com a expansão do presídio, passamos a trabalhar nas salas de aula, que eram duas, onde havia mais privacidade em comparação à estrutura da primeira sala.

Nenhuma das salas era uma "cela" de aula, configuração que tomei conhecimento ao visitar o projeto Teatro com mulheres em privação de liberdade ${ }^{17}$,

\footnotetext{
${ }^{13}$ Vários aprendizados necessários para atuar dentro do cárcere são desenvolvidos no próprio campo, sendo fundamental projetos como este para que futuras docentes possam enriquecer sua formação. Atento para isso porque, ainda, a atuação em espaços de privação de liberdade é uma exceção nas disciplinas de licenciatura em teatro, sendo, por vezes, apresentada, mas pelo viés da educação não-formal, colocando à margem a atuação nestes espaços.

14 Licencianda em Teatro pela Universidade do Estado de Santa Catarina (UDESC), iluminadora, atriz do Coletivo NEGA e, no período da pesquisa, bolsista do DEAP.

${ }^{15}$ Licenciada em Teatro pela Universidade do Estado de Santa Catarina (UDESC), atriz da Cia Caras de Bonecos.

${ }^{16}$ Mestranda em Teatro pela Universidade do Estado de Santa Catarina (UDESC), atriz e produtora do Coletivo NEGA.

${ }^{17}$ Projeto patrocinado pelo Sistema Municipal de Desenvolvimento pela Cultura da Joinville (SIMDEC).
} 
que acontecia no Presídio Regional de Joinville, realizado por Daiane Dordete ${ }^{18}$ e Samira Sinara ${ }^{19}$. No espaço que desenvolviam a oficina, as professoras ficavam separadas das estudantes por grades, sendo privadas do contato direto com as estudantes.

Essas questões estruturais podem ser consideradas entraves para o próprio trabalho, mas são as condições do mesmo dentro de instituições de privação de liberdade. Sendo assim, cabe a quem atua nesses espaços encontrar formas de trabalhar a partir desse panorama. Contudo, preciso ressaltar que não compactuo com as condições que as pessoas encarceradas são colocadas, muito menos com o discurso reformista ${ }^{20}$ das prisões. Atento apenas a esses condicionantes materiais, dado que pedem novas posturas e práticas das mediadoras em tais espaços.

Ainda, sobre as condições, em específico quanto à nossa atuação, encontramo-nos numa corda-bamba, visto que

O professor que atua no presídio está sempre no difícil papel de mostrar para as alunas que cumprem pena que ele possui um papel diferente do dos agentes penitenciários, visto que ele não é responsável por vigilância e segurança. Ao mesmo tempo, seu papel pedagógico, não raro, é visto com desconfiança pelos agentes, a quem muitas vezes não é permitido estabelecer uma relação de proximidade com as apenadas - o que poderia ser interpretado como um "afrouxamento" do papel da vigilância. (Concilio; Vetori, 2019, p. 123).

Não há, então, como desconsiderar a vigilância, base da instituição prisão, que recai em todas as envolvidas e suas ações dentro de um processo atrás das grades. Também, o duplo docilidade-utilidade, que sintetiza os objetivos de

\footnotetext{
18 Doutora em Teatro, atriz diretora, dramaturga, professora na Universidade do Estado de Santa Catarina (UDESC).

${ }^{19}$ Mestra em Patrimônio Cultural e Sociedade na Universidade da Região de Joinville (UNIVILLE), atriz e produtora cultural.

${ }^{20}$ A ideia de reforma é a perpetuação do próprio sistema, baseado em um sistema de opressões e sua continuidade. Ainda, ao pautar a humanização da prisão, esta diz respeito apenas as pessoas que estão fora - não se fala da humanização da pessoa encarcerada porque está compreensão faria ruir o próprio sistema (que para existir precisa anular a existência do outro). Como aponta Flauzina (2016), não se acabaria com o racismo no sistema penal se houve uma reforma, porque o próprio racismo é elemento estruturante da constituição deste sistema.
} 
fabricação de corpos politicamente dóceis e economicamente úteis, (Foucault, 2008), que está na gênese da instituição, torna-se perceptível na oficina, porque trabalhamos pela via corporal. Opera-se na oposição destes, visto que é

[...] o avesso do tipo de trabalho que é feito naquele espaço, preocupado que está seu corpo funcional em manter o equilíbrio da instituição mediante muita vigilância, medo e punição. E é também o avesso do que se preconiza para um processo artístico, pois em uma prisão a arte sempre vai esbarrar nos limites impostos pela política institucional que a permite existir e, para muitos, seguir fazendo arte nessas condições é render-se ao sistema que se pretende criticar. (Concilio, 2008, p. 147).

Para que se construam lampejos que suspendam tais características, a necessidade de um trabalho a longo prazo coloca-se como fundamental. Não podemos ser ingênuas no contexto de trabalho na prisão e não levar em consideração que as escolhas das pessoas com as quais trabalhamos estão orientadas a partir da negação da liberdade e, decorrente, autonomia. Uma das estratégias para a própria sobrevivência dentro da instituição, inclusive, é alinhar suas narrativas ao que os outros querem ouvir. Portanto, para a constituição de relações mínimas de confiança, há um caminho a ser trilhado por todas as envolvidas que demanda tempo.

Um dos modos de inserção no campo é partir de uma atitude de escuta, fomentando a fala e o engajamento das participantes, atitude que vai de encontro à ideia de dar voz, visto que esta expressão pode ser um ato colonizador, que corrobora para a própria manutenção dos mecanismos de poder ${ }^{21}$. Funciona, então, como uma forma de fomento e, posterior, amplificação das falas. Essa atitude, ainda, conclama um compromisso ético de quem pode trafegar extramuros, funcionando como um alto-falante das produções tecidas.

Preciso atentar que, por mais que o trabalho partisse do princípio de visibilização das mulheres encarceradas, nos registros e análises do processo, como o presente texto, não posso expor suas identidades, zelando pela segurança

${ }^{21}$ As lutas por processos de emancipação acontecem também no campo discursivo, dado que linguagem também é um mecanismo de manutenção de poder, como aponta Djamila Ribeiro, em o que é lugar de fala? (2017). 
e privacidade delas. Contudo, a compreensão das participantes como colaboradoras da pesquisa e colegas de trabalho artístico configura uma das ações na busca de outras formas de organização que pressuponham um diálogo mais horizontal. Desta forma, uma das materializações que tal compreensão ganhou foi que o registro do processo foi tecido por todas as participantes.

Lançamos mão de um diário, um caderno individual, onde cada uma foi convidada a registrar o processo e os exercícios de escrita. Além de buscar essa outra relação com as colaboradoras da pesquisa, o caderno materializava a importância do próprio registro por parte delas, de suas inscrições naquele tempo e espaço, intentando que estes não fossem nulos.

Fomentar a reapropriação de suas próprias identidades e histórias contrapõese à lógica da instituição a que estão submetidas, visto que suas identidades são sequestradas ao passo que, dentre os processos de anulação, tornam-se um número. Caminhamos, então, para a ideia de sujeitas, considerando que "têm o direito de definir suas próprias realidades, estabelecer suas próprias identidades, de nomear suas histórias." (hooks apud Kilomba, 2019, p. 28).

Investigamos, em decorrência desses questionamentos, dois vetores de criação, apontando para o convite à própria formulação de si e de mundo pelas participantes: o primeiro foi o trabalho a partir da escrita, com diferentes estímulos e proposições, e o segundo, o caminho a partir da oralidade.

Caminhos para a criação: como a escrita e o dizer de si viram saídas?

Desde o começo do nosso processo, compartilhamos proposições de escrita, focadas nas participantes e suas formulações de si e do mundo. Conceição Evaristo 22 (2009) lança mão da noção de escrevivência, a qual traz uma articulação entre o sentir, atrelado ao lugar que se ocupa no mundo, e o marcar/registrar, através da escrita. A autora aponta:

${ }^{22}$ Escritora brasileira e doutora em Literatura Comparada, pela Universidade Federal Fluminense (UFF). 
[...] quando escrevo, quando invento, quando crio a minha ficção, não me desvencilho de um 'corpo-mulher-negra em vivência' e que por ser esse "o meu corpo, e não outro", vivi e vivo experiências que um corpo não negro, não mulher, jamais experimenta. (Evaristo, 2009, p.18).

Podemos, então, articular a proposição da autora, dessa escrita a partir desses lugares de ocupação dos corpos, que apontam para o entendimento destes como lócus político, coadunando a compreensão dos saberes próprios advindos das experiências, a proposição de outras narrativas, quebrando com a história única ${ }^{23}$, e, ainda, desvelando o próprio sistema de dentro, gerando infiltrações passíveis de auxiliar no ruir dos muros.

Nos primeiros encontros, nos quais o número de participantes ainda era incerto, lançamos mão de folha soltas para nossos exercícios, iniciando com uma aproximação gradual das palavras para não distanciar as estudantes (dado que muitas não tiveram acesso à educação escolar). Passados os primeiros dois encontros, levamos ao grupo diversos cadernos, convidando-as que ali registrassem nosso percurso na oficina e os exercícios.

Uma das primeiras proposições foi a escrita de cartas: para o passado/a criança que foram; e para o futuro/a mulher que serão. Com essa proposta, fomentava a compreensão do presente como aglutinador de outras temporalidades - passado e futuro.

Caminhamos, assim, para o entendimento da memória como recriação do vivido, compreensão articulada por Patricia Leonardelli24, em A memória como recriação do vivido: um estudo da história do conceito de memória aplicado às artes performativas na perspectiva do depoimento pessoal. Nesta, a autora aponta que:

A atividade mnemônica se dá na sua prolongação com o presente, dada na experiência atual. Em parte, ela consiste em todos os conteúdos detalhadamente registrados, armazenados pelos sentidos e selecionados pelos afetos: a memória em sua acepção clássica, como persistência do

\footnotetext{
23 A escritora Chimamanda Adichie discute sobre o perigo de uma história única. Disponível em: $<$ https://www.ted.com/talks/chimamanda_ngozi_adichie_the_danger_of_a_single_story?language=pt-br\#t218434>. Acesso em: 12 out. 2020.
}

${ }^{24}$ Atriz, pesquisadora e profa. Dra. no curso de Teatro da Universidade Federal do Rio Grande do Sul (UFRGS). 
vivido. Mas ela também é criação quando se coloca em atividade para responder às necessidades do presente, oferecendo combinação de impressões como sínteses mais ou menos prováveis para a solução das questões. (Leonardelli, 2008, p. 105).

A memória, então, opera como um ato de criação do presente, explicitando seu caráter de construção, a qual pode ser felizmente transformada e ressignificada. Esse processo, de olhar para suas reminiscências, foi extremamente frutífero, sendo, inclusive, incorporado em nossa peça, que abordarei posteriormente. Ao refletir sobre a potência do exercício, acredito que soma-se, a esse ato de reapropriação narrativa e ressignificação, a familiaridade com o gênero epistolar, que as mulheres encarceradas desenvolvem, dado que é um meio de comunicação extramuros.

Algumas propostas, como a da escrita de cartas, configuraram um momento específico dentro da oficina, não dialogando diretamente com os momentos de jogos e improvisos. Outras, no entanto, decorriam diretamente da prática teatral, como foi o caso do mapeamento do grupo, inspirada nas proposições da profa. Dra. Marcia Pompeo 25 .

O mapeamento do grupo aconteceu em dois encontros. No primeiro, de modo introdutório e no segundo com reflexões sobre as questões, sendo feitas mais perguntas pelas professoras e, também, pelas próprias estudantes.

As perguntas feitas ao grupo geravam uma redistribuição espacial para que cada uma pudesse identificar as respostas das companheiras. Versavam sobre questões do âmbito individual, como gosto, mas também sobre o âmbito sociopolítico, abordando, por exemplo, configurações familiares, gênero, raça e grau de escolarização. Através da dinâmica, tivemos o reconhecimento das singularidades das participantes e, também, dos pontos em comum, na tentativa da compreensão dessas zonas de diálogo onde o "eu” transforma-se" em nós.

Após a prática, propus que anotassem o que havíamos colocado para mapear

${ }^{25}$ Atuou como professora do Departamento de Artes Cênicas da Universidade do Estado de Santa Catarina (UDESC) e do Programa de Pós-Graduação em Teatro da mesma universidade, doutora, pesquisadora em Teatro e Comunidades. Trouxe contribuições importantíssimas para a área da Pedagogia do Teatro, sendo reconhecida internacionalmente. 
nosso coletivo. Orientei que usassem o formato de formulário, o qual seria preenchido por cada uma com essas informações demandadas. Depois do preenchimento do formulário construído pelo coletivo, pedi que escolhessem dois pontos deste, os quais julgassem mais interessantes ou mesmo reveladores de quem são. Para finalizar, propus que escrevessem sobre as escolhas. Assim, fechamos a dinâmica e o processo de escrita refletindo que nossas vidas não cabiam em qualquer enquadramento, como um formulário.

Tivemos, ainda, propostas que partiram da escrita para a improvisação de cenas, como é o caso do processo com o mapa da vida, inspirado na proposição da profa. Dra. Marcia Pompeo. Em nossa proposta, não focamos em uma personagem, como é proposto pela autora, mas para o compartilhamento das próprias histórias de vida das participantes da oficina. Assim sendo, pedi que construíssem um mapa, no qual elencassem momentos marcantes de suas trajetórias.

Não falamos sobre a questão do delito ou mesmo do cárcere, para que os mapas não tivessem como eixo norteador o encarceramento. Nos mapas, contudo, foi recorrente o registro do encarceramento, acredito que em decorrência de ser um momento que ainda viviam. Ainda, vários mapas traziam a sinalização da gravidez.

Vários tinham menções ao contato com as drogas, o abandono familiar e o abandono da escola, questões que estão vinculadas ao perfil de encarceradas, aludindo a um quadro maior. Em um deles, de modo explícito, havia a sinalização da violência doméstica. Assim, vários foram os marcadores do passado, mas houve o registro por parte de algumas da entrada na oficina de teatro, sendo uma sinalização da ordem do presente. Ainda, em um dos mapas, houve a sinalização de uma projeção de futuro, a liberdade condicional.

Após criarmos nossos mapas da vida, compartilhamos em pequenos grupos, na busca por pontos comuns. Cada grupo, a partir das trocas tecidas, criou improvisos, que inspiraram a própria criação cênica.

Além dessas proposições do campo da escrita, o outro vetor de criação de 
materiais para a composição cênica foi a oralidade. Um dos jogos propostos foi que, em duplas, cada uma das estudantes contaria duas histórias, uma verdadeira e outra falsa. Após, ainda em duplas, decidiriam qual história iriam levar para o compartilhamento com as demais. Depois de fazermos essa proposta, tomei conhecimento de que a profa. Dra. Marcia Pompeo propunha o jogo histórias de mentira e histórias de verdade, investigando a relação entre realidade e imaginação. (Pompeo, 2011).

No momento de compartilhamento cênico, todas lançaram mão de histórias verdadeiras, acredito que revelando a vontade de compartilhar suas vidas. Talvez, isso decorra de, no enquadramento prisional, não terem muitos momentos de troca, sendo uma exceção o interesse em suas trajetórias. A comicidade era presente, suponho que como um modo de encaminhamento de um histórico de vida difícil, sendo o riso uma forma de ressignificação das vivências.

Outra dinâmica proposta foi a contação de história coletiva, sendo esta mediada por Thaunny Paes. Aqui, numa roda, uma pessoa começava a contar uma história que era continuada pela pessoa ao lado, até completar o círculo e passar a palavra (criadora) por todas da roda. Então, criava-se, coletivamente, em improvisação, a história que primeiramente construíram na narração.

Coletivamente criamos, em uma das rodadas, uma história muito poética, posteriormente chamada por nós de História da chuva. Nela, havia várias metáforas e temáticas urgentes e interessantes a serem compartilhadas, tais como, segundo Concilio (2020), a superação dos obstáculos do caminho, as supostas facilidades, os erros e decorrentes consequências e a importância e necessidade da segunda chance.

Essa proposição é frutífera em diversos sentidos, como para ativar o estado de jogo, convocando a imaginação, dado que não sabemos como a história chegará a nós, não sendo possível criar antes de seu momento de contribuição; para convocar a escuta, da qual emerge a criação, sendo de fato fundamental a escuta das colegas de jogo; para fomentar a construção coletiva, dado que a história é deveras composta de muitas vozes. 
A história tinha tanta força poética que foi usada como base para a construção dramatúrgica. Antes, tivemos outros desdobramentos da história, como a escrita dela na forma de um conto e a criação de imagens de alguns momentos da narrativa.

Segundo Jeanne Marie Gagnebin²6 (2006), o exercício da escrita se coloca diante da ameaça do esquecimento e do silêncio (em nosso caso, o correto é dizer silenciamento). Assim, os modos de lembrar, através da escrita e/ou da oralidade, são fundamentais para a construção (que, no contexto da prisão, se dá primeiro pela via da reapropriação) das identidades (Gagnebin, 2006). O campo poético, então, pode corroborar para a reapropriação e ressignificação das histórias e das identidades, contrapondo-se à mortificação do eu (Goffman, 2001) produzida pela prisão.

Durante nosso processo tivemos momentos de conversa que foram muito importantes para uma construção coletiva que considerasse as demandas de todas as envolvidas.

Em uma das conversas, debatemos sobre o uso das histórias de vida, que fora problematizado por algumas mulheres. Algumas não se sentiam à vontade para expor suas histórias e outras apontavam que haveria um panorama de expectativa por parte das futuras espectadoras sobre o que elas iriam produzir, sendo frutífero quebrarmos com esta expectativa, na busca por abrir proposições mais interessantes que não estivessem assentadas em estereótipos.

Nesse processo, então, eu mesma me confrontei com as ideias préconcebidas, ao pautar que as histórias de vida em si seriam o substrato para a composição dramatúrgica e cênica. Como havíamos construído um espaço de trocas e, aos poucos, chegamos em uma relação de parceria de trabalho, as questões colocadas pelas participantes da oficina expandiram a proposição, tornando-a mais interessante. Novamente, a escuta fez-se primordial não apenas na tessitura das materialidades engendradas, mas no próprio processo.

Então, a partir dos diversos materiais gerados e do processo em si, busquei

${ }^{26}$ Filósofa suíça e professora da Pontifícia Universidade Católica de São Paulo (PUC-SP). 
uma articulação que desse conta de trazer aquele(s) mundo(s), sem reforçar os estereótipos e mesmo as expectativas que as pessoas têm do universo da prisão.

Dramaturgia da escuta: seria a escuta uma chave para a construção dramatúrgica?

Primeiramente, em consonância com Holloway (2013), aponto para a escuta como focal, dado o contexto de trabalho, no qual as participantes da oficina estavam submetidas. Assim sendo, propus que operássemos a partir da recusa ao modo de funcionamento da instituição prisão, mas lançando mão de ação. Ação que explicita as próprias mulheres encarceradas como produtoras de criações, que podem corroborar para outras aberturas de mundo, tensionando a partir de dentro do sistema prisional.

Em relação à ideia de dramaturgia da escuta, inspirei-me na compreensão de Alessandro Portelli ${ }^{27}$ sobre história oral como arte da escuta. O autor foca na escuta como constitutiva na construção dos materiais e conhecimentos gerados entre a pesquisadora e a pessoa entrevistada, em estudos que lançam mão da história oral. Desta forma, ao compreender a dramaturgia como lugar de escuta salientam-se as vozes participantes do processo em um primeiro plano e não a própria dramaturga.

Ainda, a partir de Gayatri Spivak ${ }^{28}$ (2010) que lancei mão da ideia de dramaturgia da escuta, dada a abertura de um lugar para que essas vozes possam emergir, visto que a autora salienta que cabe àquelas que ocupam espaços de produção de conhecimento lutar contra os processos de subalternização, fomentando espaços nos quais as próprias pessoas possam construir suas formulações de mundo.

Por vezes, a construção dramatúrgica parece uma proposição apenas textual, como se a dramaturga falasse a partir de um texto, estando menos explícitas

\footnotetext{
${ }^{27}$ Historiador e professor na Universidade Sapienza, em Roma.

28 Teórica literária, crítica feminista e professora na Universidade Columbia, em Nova Iorque.
} 
outras vozes que compuseram o processo. E se pensarmos, sobretudo em casos que o texto advém de um percurso com grupos subalternizados, a dramaturga como aquela que escuta e articula na tessitura textual as diferentes vozes que compuseram o trabalho? Acredito que essa sutil mudança de eixo em trabalhos com grupos oprimidos, que são paulatinamente silenciados e/ou não escutados seja frutífera, abrindo espaços para que estes possam engendrar suas próprias formulações. Essa compreensão foi crucial durante o processo de geração de materiais e após o diálogo com os mesmos.

Embasar o trabalho na escuta dá-se pela importância e urgência de afirmar que existem falas na sociedade que são silenciadas e/ou não escutadas. Também, quanto a minha postura no trabalho, o entendimento trazido por Djamila Ribeiro (2017, p. 78), a partir de Grada Kilomba, de que "é necessário escutar por parte de quem sempre foi autorizado a falar”. Compreensão que convoca outra relação no trabalho de composição, de acolhida dessas vozes que são presentes, mas estruturalmente não são escutadas.

Para explicitar como operou a escuta, apresento exemplos a partir de excertos da dramaturgia. Na dissertação Estendemos nossas memórias ao sol: caminhos para uma dramaturgia da escuta com mulheres em privação de liberdade 29 , a escritura dramatúrgica é compartilhada e analisada à luz dessa ótica. A peça começa com endereçamento direto às espectadoras:

Atriz a - Então, oi. Boa tarde. A gente tá bem feliz que vocês vieram. A gente tá... bem feliz... que vocês... vieram (sorriso "amarelo"), mas acontece que (gesticula como se tentasse desenvolver, mas não conseguisse)... Como é que a gente diz isso?! Sendo que vocês estão aqui... e a gente tá bem feliz, bem feliz mesmo... mas acontece que

Atriz b (interrompendo) - Não teremos espetáculo. Pronto, foi. ${ }^{30}$

A partir das conversas com as participantes e colaboradoras, foi colocada a questão da espetacularização de suas vidas, bem como uma ideia pré-concebida

${ }^{29}$ Dissertação defendida em 2020, desenvolvida na Universidade do Estado de Santa Catarina (UDESC), sob orientação do prof. Dr. Vicente Concilio.

30 Trecho retirado da peça Estendemos nossas memórias ao sol. Destaques conforme o original. 
do que elas produziriam. Assim, essa cena já propõe outra dinâmica, sendo fruto direto do processo de escuta das mulheres com as quais trabalhei. Também, alinha-se à compreensão de que há panorama de produções visuais da prisão que corroboram para a naturalização da instituição. Quebra-se, desta forma, com essa lógica, propondo uma relação que pode esboçar novos imaginários.

Ainda sobre a inclusão de questões levantadas pelas mulheres em situação de cárcere ao longo do processo, em conversas, uma das estudantes disse que não seria interessante compartilharem suas histórias de vida porque não tinham ainda um momento de redenção, como o finalização do período na instituição, que ela julgava necessário. Debatemos sobre a questão processual de estar viva, que aponta para a ideia de construção contínua como sujeitas.

Na dramaturgia, dentro da dinâmica do mapeamento coletivo, levamos essa discussão ao público - sobre estarem ou não prontas:

Atriz a - Nós estamos qua-se prontas, logo não teremos espetáculo, entende?!

Atriz d - Eu não sei se me encaixo no quase.

Atriz e - Eu também não.

Atriz c - Quem se encaixa no quase pronta?

Entram as demais atrizes e se distribuem nas "categorias".

Atriz a - Pra lá quem tá quase, pra ali quem tá pronta total e ali quem não tá definitivamente pronta. ${ }^{31}$

O texto funciona, também, como uma interface de diálogo com as espectadoras. Na busca pela construção de novos imaginários, compartilhamos as perguntas que nos atravessaram, propondo mais do que fechar questões, abri-las no espaço público: estender memórias ao sol para que estas não sigam obscurecidas no debate público.

Outra cena que julgo interessante compartilhar é a leitura das cartas, visto que elucida outra forma de operar, através da inserção de materiais brutos na

${ }^{31}$ Trecho retirado da peça Estendemos nossas memórias ao sol. Destaques conforme o original. 
peça. Ao compreender a potência das cartas, estas foram incorporadas na íntegra, com sua leitura direta ao próprio público. Esse momento tensiona a trama ficcional, com a entrada das próprias atrizes (e não personagens) que compartilham suas cartas para o passado. A escuta nessa passagem, de forma explícita, projeta-se para fora do próprio processo, na relação com as espectadoras, convocando destas uma abertura e qualidade de presença próprias da escuta.

\section{Conclusões: a finalidade seria a abertura?}

Muitos são os entraves para trabalhar dentro do contexto carcerário, mas, acredito, que deve ser lembrada a importância de trabalhos que, minimamente, tensionam a instituição, com ações para a promoção da autonomia, bem como lembrar para quem, em primeira instância, o trabalho se destina.

Há um trabalho que ocorre no subterrâneo de toda nossa atuação: o fomento à autonomia. Ainda, ao pautar as histórias de vida como focais, vislumbramos outras possibilidades de futuro e, segundo Marinês da Rosa ${ }^{32}$, essa projeção auxilia para "encontrar sentido para a atual condição de vida e não fragmentar e resumir sua vivência ao estágio prisional.” (Rosa, 2019, p. 12).

Na abordagem a partir da escuta chamo a atenção para a abertura de espaços nos quais as próprias participantes possam gerar suas formulações e ocupar a centralidade na enunciação e o decorrente protagonismo em todas as instâncias da criação cênica. Também, atento para a contribuição da abordagem no fomento de outra relação entre as participantes e as condutoras do processo, enquanto parcerias de trabalho.

Se a prisão opera forjando ausências o terreno artístico pode ser um catalizador de presenças, fazendo ecoar suas vozes e narrativas para além muros. Para Davis (2018, p.22), “o desafio mais difícil e urgente hoje é explorar de maneira

32 Mestra em Sociologia Política e doutoranda em Ciências Humanas, ambas pela Universidade Federal de Santa Catarina (UFSC). 
criativa novos terrenos para a justiça nos quais a prisão não seja mais nossa principal âncora”. A proposição de novos imaginários, como na presente pesquisa, pode auxiliar nesse processo, abrindo outras possibilidades de realidades.

Nós tivemos duas oportunidades de apresentar fora do presídio a peça fruto do trabalho compartilhado neste artigo, intitulada Estendemos nossas memórias ao sol. Uma delas em um festival, o Festival Isnard Azevedo -Floripa Teatro ${ }^{33} \mathrm{e}$ outra dentro da UDESC, integrando a mostra do evento 3 anos do projeto: Mulheres Negras Resistem ${ }^{34}$.

Sobre o festival, é importante compartilhar que foi a primeira vez que um coletivo formado por mulheres em situação de cárcere conquistou o direito judicial de se apresentar fora da prisão, no referido festival, envolvendo questões maiores que a própria criação de uma peça. Como compartilha Concilio (2020), tivemos a confiança da direção do Presídio nesse trabalho artístico e formativo, justamente em momento político que setores conservadores atacam o trabalho desenvolvido nas universidades e propagam discursos de ódio, fazendo coro ao projeto de encarceramento em massa.

Uma das características do evento teatral é que este só acontece na relação direta com as espectadoras, no momento da apresentação. Assim, com um grupo formado por mulheres em situação de cárcere, que foram alijadas do convívio social, o encontro torna-se ainda mais potente.

As apresentações revelam-se como pretexto para gerarmos encontros: as mulheres encontram-se com pessoas que não viam há tempos e, mais, fora do enquadramento prisional. Após a primeira apresentação, tivemos a oportunidade de conversar com o grupo sobre a experiência e convidá-las a fazer alguns registros escritos. Neles, em primeiro plano estava a satisfação em serem reconhecidas de outro modo, não a partir da condição do encarceramento.

O público, a partir do convite a um trabalho produzido por mulheres privadas

\footnotetext{
${ }^{33}$ A apresentação aconteceu no dia 28 de setembro de 2019, no Teatro da UBRO.

${ }^{34}$ Evento proposto pelo Coletivo NEGA (Negras Experimentações Grupo de Arte), contemplado pelo Fondo de Mujeres del Sur. A apresentação aconteceu no dia 29 de movimento de 2019, no Centro de Artes da UDESC.
} 
de liberdade, por vezes, crê que encontrará presas. No entanto, surpreende-se ao se deparar com artistas - surpresa que evidencia os estereótipos e estigmas perpetrados em relação às pessoas que cometeram algum delito. Desta forma, a relação com o público gera uma virada social, pedagógica e ética, para além da própria experiência estética.

Evidencia-se a

[...] habilidade da arte em produzir sentidos além dos explicados pelos elementos materiais e textuais da cena, essa capacidade de construir significados outros diante do espectador constitui-se em uma das fissuras possíveis que escapam ao controle do sistema penal." (Concilio, 2008, p. 153).

A arte, então, comprova sua potência como catalizadora de mudanças de imaginário e, também, como produtora de fissuras, decorrentes de uma proposição assentada no duplo recusa-e-criação. (Holloway, 2013).

Pequenas grandes fissuras abertas por muitas, mas, sobretudo, pelas próprias mulheres que têm a vida marcada pelo cárcere, resistindo aos processos de desumanização e de morte de suas existências. Caminhei ao lado delas, compreendendo, conforme Ribeiro (2017), que poder falar não se restringe ao ato de emitir palavras, mas a poder existir, sendo a escuta primordial. Elas, em cena, puderam dizer que existem, resistem e insistem (contra o concreto que ainda irá ruir).

\section{Referências}

DAVIS, Angela. Estarão as prisões obsoletas?. Tradução: Marina Vargas. Rio de Janeiro: Difel, 2018.

CONCILIO, Vicente. Teatro e prisão: dilemas da liberdade artística. São Paulo, Hucitec, 2008.

CONCILIO, Vicente. Criar atrás das grades, libertar-se das paredes: desafios da cena construída no Presídio Feminino de Florianópolis. Caixa de Ponto, 
Florianópolis, n.11, p.20, 2020. Disponível em: < https://7def63e5-712c-41aab56cd66c7d4ff3e2.filesusr.com/ugd/23361d_8a8c4691e74d4976919eaae980363ed 5.pdf >Acesso em: 10 out. 2020.

CONCILIO, Vicente; VETORI, Caroline. Relato solto de uma oficina atrás das grades: um processo de escrita teatral dentro do Presídio Feminino de Florianópolis. laçá Artes da Cena, Amapá, v.2, n.2, p.120-132, 2019. Disponível em: <https://periodicos.unifap.br/index.php/iaca/article/view/5088> Acesso em: 10 out. 2020.

EVARISTO, Conceição. Literatura negra: uma poética de nossa afro-brasilidade. SCRIPTA, Belo Horizonte, v. 13, n. 25, p. 17-31, 2o sem. 2009.

FLAUZINA, Ana Luiza Pinheiro. Corpo negro caído no chão: o sistema penal e o projeto genocida do Estado brasileiro. Dissertação (Mestrado em Direito) Faculdade de Direito, Universidade de Brasília. Brasília. p. 145. 2006 Disponível em: <http://repositorio.unb.br/handle/10482/5117>. Acesso em: 12 dout. 2020.

FOUCAULT, Michel. Vigiar e punir. nascimento da prisão. Tradução: Raquel Ramalhete. Rio de Janeiro: Vozes, 2008.

GAGNEBIN, Jeanne Marie. Lembrar, escrever, esquecer. São Paulo: Editora 34, 2006.

GOFFMAN, Erving. Estigma: notas sobre a manipulação da identidade deteriorada. Tradução: Márcia Bandeira de Mello Leite Nunes. Rio de Janeiro: LTC, 1975.

GOFFMAN, Erving. Manicômios, prisões e conventos. Tradução: Dante Moreira Leite. São Paulo: Perspectiva, 2001.

HOLLOWAY, John. Fissurar o capitalismo. Tradução: Daniel Cunha. São Paulo: Publisher, 2013.

KILOMBA, Grada. Memórias da plantação: episódios de racismo cotidiano. Tradução: Jess Oliveira. Rio de Janeiro: Cobogó. 2019.

LEONARDELLI, Patricia. A memória como recriação do vivido: um estudo da história do conceito de memória aplicado às artes performativas na perspectiva do depoimento pessoal. Tese (Doutorado em Artes Cênicas) - Escola de Comunicações e Artes, Universidade de São Paulo. São Paulo. p. 236. 2008.

POMPEO, Marcia. Pistas para pesquisa de uma comunidade como base para um trabalho teatral. Anais ABRACE, v. 12, n. 1, 2011.

PORTELLI, Alessandro. História oral como arte da escuta. Tradução: Ricardo Santhiago. São Paulo: Letra e Voz, 2016. 
RIBEIRO, Djamila. O que é lugar de fala?. Belo Horizonte: Letramento. 2017.

ROSA, Marinês. A escrita de si entre mulheres encarceradas: a experiência metodológica com recurso da literatura marginal. Disponível em: < http://www.sbs2019.sbsociologia.com.br/arquivo/downloadpublic?q=YToyOntzOjY 6InBhcmFtcyl7czozNToiYToxOntzOjEwOiJJRF9BULFVSVZPIjtzOjQ6ljEwMDgiO30iO3 M6MToiaCI7czozMjoiZWYOMTY1MjJkOTUOMjcXMTRmYZI1NDU3OWVjNWQZYWMiO3 0\%3D > Acesso em: 10 jan. 2020.

SPIVAK, Gayatri Chakravorty. Pode o subalterno falar?. Tradução: Sandra Regina Goulart Almeida, Marcos Pereira Feitosa, André Pereira Feitosa. Belo Horizonte: UFMG, 2010.

Recebido em: 15/10/2020

Aprovado em: 26/11/2020 